\title{
Lower Bound for the Radiation $\$ Q \$$ of Electrically Small Magnetic Dipole Antennas With Solid Magnetodielectric Core
}

Kim, Oleksiy S.; Breinbjerg, Olav

Published in:

I E E E Transactions on Antennas and Propagation

Link to article, DOI:

10.1109/TAP.2010.2096394

Publication date:

2011

Document Version

Publisher's PDF, also known as Version of record

Link back to DTU Orbit

Citation (APA):

Kim, O. S., \& Breinbjerg, O. (2011). Lower Bound for the Radiation \$Q\$ of Electrically Small Magnetic Dipole Antennas With Solid Magnetodielectric Core. I E E E Transactions on Antennas and Propagation, 59(2), 679681. https://doi.org/10.1109/TAP.2010.2096394

\section{General rights}

Copyright and moral rights for the publications made accessible in the public portal are retained by the authors and/or other copyright owners and it is a condition of accessing publications that users recognise and abide by the legal requirements associated with these rights.

- Users may download and print one copy of any publication from the public portal for the purpose of private study or research.

- You may not further distribute the material or use it for any profit-making activity or commercial gain

- You may freely distribute the URL identifying the publication in the public portal 
[4] K. L. Wong and S. J. Liao, "Uniplanar coupled-fed printed PIFA for WWAN operation in the laptop computer," Microwave Opt. Technol Lett., vol. 51, pp. 549-554, Feb. 2009.

[5] K. L. Wong and L. C. Lee, "Multiband printed monopole slot antenna for WWAN operation in the laptop computer," IEEE Trans. Antennas Propag., vol. 57, pp. 324-330, Feb. 2009.

[6] C. Zhang, S. Yang, S. El-Ghazaly, A. E. Fathy, and V. K. Nair, "A lowprofile branched monopole laptop reconfigurable multiband antenna for wireless applications," IEEE Antennas Wireless Propag. Lett., vol. 8, pp. 216-219, 2009.

[7] K. L. Wong and F. H. Chu, "Internal planar WWAN laptop computer antenna using monopole slot elements," Microwave Opt. Technol Lett., vol. 51, pp. 1274-1279, May 2009.

[8] C. W. Chiu, Y. J. Chi, and S. M. Deng, "An internal multiband antenna for WLAN and WWAN applications," Microwave Opt. Technol Lett., vol. 51, pp. 1803-1807, Aug. 2009.

[9] C. T. Lee and K. L. Wong, "Study of a uniplanar printed internal WWAN laptop computer antenna including user's hand effects," Microwave Opt. Technol Lett., vol. 51, pp. 2341-2346, Oct. 2009.

[10] , S. Sesia, I. Toufik, and M. Baker, Eds., LTE, The UMTS Long Term Evolution: From Theory to Practice. New York: Wiley, 2009.

[11] C. T. Lee and K. L. Wong, "Uniplanar printed coupled-fed PIFA with a band-notching slit for WLAN/WiMAX operation in the laptop computer," IEEE Trans. Antennas Propag., vol. 57, pp. 1252-1258, Apr. 2009.

[12] C. H. Wu and K. L. Wong, "Ultra-wideband PIFA with a capacitive feed for penta-band folder-type mobile phone antenna," IEEE Trans. Antennas Propag., vol. 57, pp. 2461-2464, Aug. 2009.

[13] C. T. Lee and K. L. Wong, "Internal WWAN clamshell mobile phone antenna using a current trap for reduced groundplane effects," IEEE Trans. Antennas Propag., vol. 57, pp. 3303-3308, Oct. 2009.

[14] K. L. Wong and C. H. Huang, "Bandwidth-enhanced internal PIFA with a coupling feed for quad-band operation in the mobile phone," Microwave Opt. Technol. Lett., vol. 50, pp. 683-687, Mar. 2008.

[15] C. H. Chang, K. L. Wong, and J. S. Row, "Coupled-fed small-size PIFA for penta-band folder-type mobile phone application," Microwave Opt. Technol. Lett., vol. 51, pp. 18-23, Jan. 2009.

[16] C. T. Lee and K. L. Wong, "Uniplanar coupled-fed printed PIFA for WWAN/WLAN operation in the mobile phone," Microwave Opt. Technol. Lett., vol. 51, pp. 1250-1257, May 2009.

[17] T. W. Kang and K. L. Wong, "Simple small-size coupled-fed uniplanar PIFA for multiband clamshell mobile phone application," Microwave Opt. Technol. Lett., vol. 51, pp. 2805-2810, Dec. 2009.

[18] C. H. Chang and K. L. Wong, "Printed $\lambda / 8$-PIFA for penta-band WWAN operation in the mobile phone," IEEE Trans. Antennas Propag., vol. 57, pp. 1373-1381, May 2009.

[19] K. L. Wong and C. H. Huang, "Compact multiband PIFA with a coupling feed for internal mobile phone antenna," Microwave Opt. Technol. Lett., vol. 50, pp. 2487-2491, Oct. 2008.

[20] W. J. Tseng, "Coupled-Fed Antenna Device," U.S. Patent 2007/ 0257842 A1, Nov. 8, 2007.

[21] L. Lu and J. C. Coetzee, "A modified dual-band microstrip monopole antenna," Microwave Opt. Technol. Lett., vol. 48, pp. 1401-1403, Jul. 2006.

[22] R. Borowiec and P. M. Slobodzian, "A miniaturized antenna for $2 \mathrm{G} / 3 \mathrm{G}$ frequency-based applications," Microwave Opt. Technol. Lett., vol. 48, pp. 399-402, Feb. 2006.

[23] C. R. Rowell and R. D. Murch, "A compact PIFA suitable for dualfrequency 900/1800-MHz operation," IEEE Trans. Antennas Propag., vol. 46, pp. 596-598, Apr. 1998.

[24] [Online]. Available: http://www.ansoft.com/products/hf/hfss/Ansoft Corporation HFSS

[25] S. Y. Lin, "Multi-band folded planar monopole antennas for mobile handset," IEEE Trans. Antennas Propag., vol. 52, pp. 1790-1794, Jul. 2004.

[26] C. Zhang, S. Yang, S. El-Ghazaly, A. E. Fathy, and V. K. Nair, "A lowprofile branched monopole laptop reconfigurable multiband antennas for wireless applications," IEEE Antennas Wireless Propag. Lett., vol. 8, pp. 216-219, 2009.

[27] J. Guterman, A. A. Moreira, C. Peixeiro, and Y. Rahmat-Samii, "Wrapped microstrip antennas for laptop computers," IEEE Antennas Propag. Mag., vol. 51, pp. 12-39, Aug. 2009.

\section{Lower Bound for the Radiation $Q$ of Electrically Small Magnetic Dipole Antennas With Solid Magnetodielectric Core}

\author{
Oleksiy S. Kim and Olav Breinbjerg
}

\begin{abstract}
A new lower bound for the radiation $Q$ of electrically small spherical magnetic dipole antennas with solid magnetodielectric core is derived in closed form using the exact theory. The new bound approaches the Chu lower bound from above as the antenna electrical size decreases. For $k a<0.863$, the new bound is lower than the bounds for spherical magnetic as well as electric dipole antennas composed of impressed electric currents in free space.
\end{abstract}

Index Terms-Chu lower bound, electrically small antennas, fundamental limitations, magnetic dipole, quality factor.

\section{INTRODUCTION}

An ideal electrically small magnetic dipole antenna composed of an impressed electric current on the surface of an imaginary sphere exhibits a radiation $Q$ three times the Chu lower bound [1], [2]. When the surface current encloses a magnetic core the internal stored magnetic energy reduces, and the Chu lower bound [3] can be reached for a vanishingly small antenna. However, the behavior of a finite-size magnetic dipole antenna is more complicated due to the internal resonances in the magnetic core. Exact analytical expressions derived in [4] show that the minimum achievable $Q$ is a function of the antenna electrical size. This function represents the lower bound for the radiation $Q$ of a magnetic dipole antenna with a magnetodielectric core. In this communication, taking account of the rigorous theory presented in [4], we derive an analytical expression for this lower bound and define its range of validity.

\section{LOWER BOUND FOR THE QUALITY FACTOR}

We consider an impressed electric current on the surface of a material spherical core with relative permeability $\mu_{\mathrm{r}}$ and permittivity $\varepsilon_{\mathrm{r}}$. In a spherical coordinate system $(r \theta \phi)$ the surface current density radiating the $\mathrm{TE}_{10}$ spherical mode (magnetic dipole mode) is

$$
\mathbf{J}=\hat{\mathbf{a}}_{\phi} J_{0} \sin \theta
$$

where $\hat{\mathbf{a}}_{\phi}$ is the azimuthal unit vector and $J_{0}$ is the amplitude $(\mathrm{A} / \mathrm{m})$. Closed-form expressions for the stored magnetic $W_{\mathrm{H}}$ and electric $W_{\mathrm{E}}$ energies as well as for the radiated power $P_{\text {rad }}$ are derived in [4]. From those, the radiation quality factor $Q$ can be expressed in compact form, subject to $W_{\mathrm{H}} \geq W_{\mathrm{E}}$, as

$$
Q\left(k a, \mu_{\mathrm{r}}, \varepsilon_{\mathrm{r}}\right)=\left\{1+\frac{1}{\mu_{\mathrm{r}}} \Lambda\left(k_{s} a\right)\right\} Q_{\mathrm{Chu}}(k a)
$$

where $k$ is free-space wave number, $a$ is the radius of the antenna, $k_{s}=$ $\sqrt{\varepsilon_{\mathrm{r}} \mu_{\mathrm{r}}} k$ is the wave number in the core material, the function $\Lambda\left(k_{s} a\right)$

$$
\Lambda\left(k_{s} a\right)=\frac{1+\left(k_{s} a\right) j_{0}\left(k_{s} a\right) y_{0}\left(k_{s} a\right)}{2 j_{1}^{2}\left(k_{s} a\right)}-1
$$

Manuscript received February 17, 2010; revised June 24, 2010; accepted August 31, 2010. Date of publication December 03, 2010; date of current version February 02, 2011. This work was supported by the Danish Research Council for Technology and Production Sciences within the TopAnt project.

The authors are with the Department of Electrical Engineering, Electromagnetic Systems, Technical University of Denmark, DK-2800 Kgs. Lyngby, Denmark (e-mail: osk@elektro.dtu.dk; ob@elektro.dtu.dk).

Digital Object Identifier 10.1109/TAP.2010.2096394 


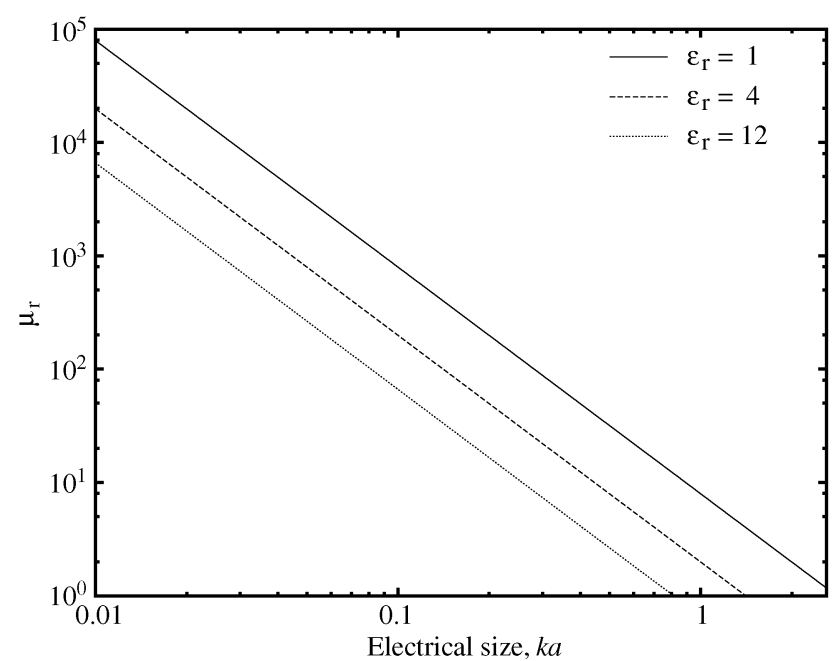

Fig. 1. Optimum permeability (8) as a function of the antenna electrical size $k a$ for $n=1$ and $\varepsilon_{\mathrm{r}}=1,4,12$.

$j_{n}(x)$ and $y_{n}(x)$ are the $n$-order spherical Bessel functions of the first and second kind, respectively, and $Q_{\mathrm{Chu}}$ is the Chu lower bound [3], [5]

$$
Q_{\mathrm{Chu}}(k a)=\frac{1}{(k a)^{3}}+\frac{1}{k a} .
$$

In the limiting case of a vanishingly small antenna, expression (2) reduces to the well-known formula by Wheeler [1]

$$
\lim _{k a \rightarrow 0} Q\left(k a, \mu_{\mathrm{r}}, \varepsilon_{\mathrm{r}}\right)=Q\left(k a, \mu_{\mathrm{r}}\right)=\left(1+\frac{2}{\mu_{\mathrm{r}}}\right) \frac{1}{(k a)^{3}} .
$$

For a finite-size antenna, the function $\Lambda\left(k_{s} a\right)$ exhibits singularities at zeroes of the Bessel function $j_{1}\left(k_{s} a\right)$, and, consequently, so does the quality factor $Q$ in (2). The singularities originate from the internal $\mathrm{TE}_{10}$-mode resonances in the spherical core, when the external fields, and thus the radiated power, are zero. To find the minimum $Q$ between the resonances and the corresponding optimal permeability of the core, we have to solve the following equation

$$
\frac{\partial Q\left(k a, \mu_{\mathrm{r}}, \varepsilon_{\mathrm{r}}\right)}{\partial \mu_{\mathrm{r}}}=0 .
$$

Substituting (2) into (6) and letting $u=k_{s} a$, we obtain

$$
\frac{u}{2} \frac{\partial \Lambda(u)}{\partial u}-\Lambda(u) \equiv \frac{F_{1}(u)}{F_{2}(u)}=0 .
$$

This equation has an infinite number of solutions-zeroes $u_{n}(n=$ $1,2,3, \ldots)$ of the oscillating function $F_{1}(u)$. The corresponding optimal permeability is then found as

$$
\mu_{\mathrm{r}}\left(k a, \varepsilon_{\mathrm{r}}\right)=\frac{u_{n}^{2}}{\varepsilon_{\mathrm{r}}(k a)^{2}}
$$

and illustrated in Fig. 1.

Obviously, for each solution $u_{n}$ there is a corresponding quality factor $Q_{n}(k a)$, which can be obtained from (2) taking into account (8) as

$$
\begin{aligned}
Q_{n}\left(k a, \varepsilon_{\mathrm{r}}\right) & =\left\{1+(k a)^{2} \varepsilon_{\mathrm{r}} \frac{\Lambda\left(u_{n}\right)}{u_{n}^{2}}\right\} Q_{\mathrm{Chu}}(k a) \\
& \equiv\left\{1+(k a)^{2} \varepsilon_{\mathrm{r}} \lambda_{n}\right\} Q_{\mathrm{Chu}}(k a) .
\end{aligned}
$$

TABLE I

ZEROS $u_{n}$ OF THE FUNCTION $F_{1}(u)$ IN (7) AND THE CORRESPONDING CONSTANTS $\lambda_{n}$ IN (9)

\begin{tabular}{l|c|c|c|r}
\hline$n$ & 1 & 2 & 3 & \multicolumn{1}{c}{4} \\
\hline$u_{n}$ & 2.8161 & 6.1915 & 9.3684 & 12.5252 \\
$\lambda_{n}$ & 0.3658 & 0.4707 & 0.4872 & 0.4928 \\
\hline
\end{tabular}

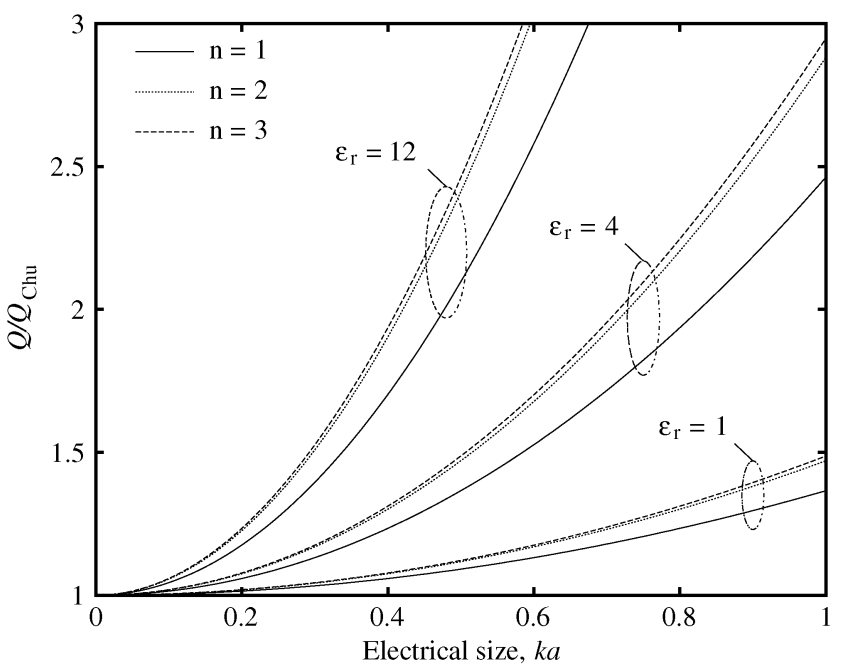

Fig. 2. Normalized quality factor $Q_{n} / Q_{\mathrm{Chu}}$ (9) corresponding to the optimum permeability (8) for $n=1,2,3$ and $\varepsilon_{\mathrm{r}}=1,4,12$.

The first four values of $u_{n}$ and the corresponding constants $\lambda_{n}$ are given in Table I. From Table I as well as from Fig. 2, which illustrates the expression (9), it is clear, that the first value $u_{1}$ yields the lowest $\lambda_{n}$, and, consequently, the lowest $Q_{n}\left(k a, \varepsilon_{\mathrm{r}}\right)$. Since the $Q_{n}\left(k a, \varepsilon_{\mathrm{r}}\right)$ also reduces as the permittivity $\varepsilon_{\mathrm{r}}$ decreases, the optimal core must be pure magnetic with relative permeability

$$
\mu_{\mathrm{r}}(k a)=\frac{u_{1}^{2}}{(k a)^{2}} .
$$

Finally, the lower bound for magnetic dipole antennas can be written from (9) as

$$
\begin{aligned}
Q_{\mathrm{LB}}(k a) & =Q_{1}\left(k a, \varepsilon_{\mathrm{r}}=1\right) \\
& =\left\{1+(k a)^{2} \lambda_{1}\right\} Q_{\mathrm{Chu}}(k a) \\
& =\frac{1}{(k a)^{3}}+\frac{\lambda_{1}+1}{k a}+(k a) \lambda_{1} .
\end{aligned}
$$

The conclusion is that for a given antenna electrical size $k a$ there is an optimum magnetic core permeability (10) that ensures the lowest possible $Q$ as given in (11). This $Q$ is thus the lower bound for magnetic dipole antennas with solid magnetodielectric core.

As illustrated in Fig. 3, the new bound (11) is higher than the Chu lower bound, but approaches it as $k a \rightarrow 0$. At the same time, it shows that with a properly selected magnetic core an electrically small magnetic dipole antenna exhibits a $Q$ that is lower not only as compared to the same antenna with air core, but also as compared to an air-core electric dipole antenna ${ }^{1}$ of the same size. We note, however, that in a region $0.863<k a<1.325$-although, in this region an antenna can hardly be considered electrically small—an air-core electric dipole antenna performs slightly better.

${ }^{1}$ Here, and throughout the communication, we assume that air-core magnetic and electric dipole antennas are composed of electric current distributions on an imaginary spherical surface in free space, that is, no other materials or objects, neither inside, nor on the surface, nor outside of the antenna, are present. 


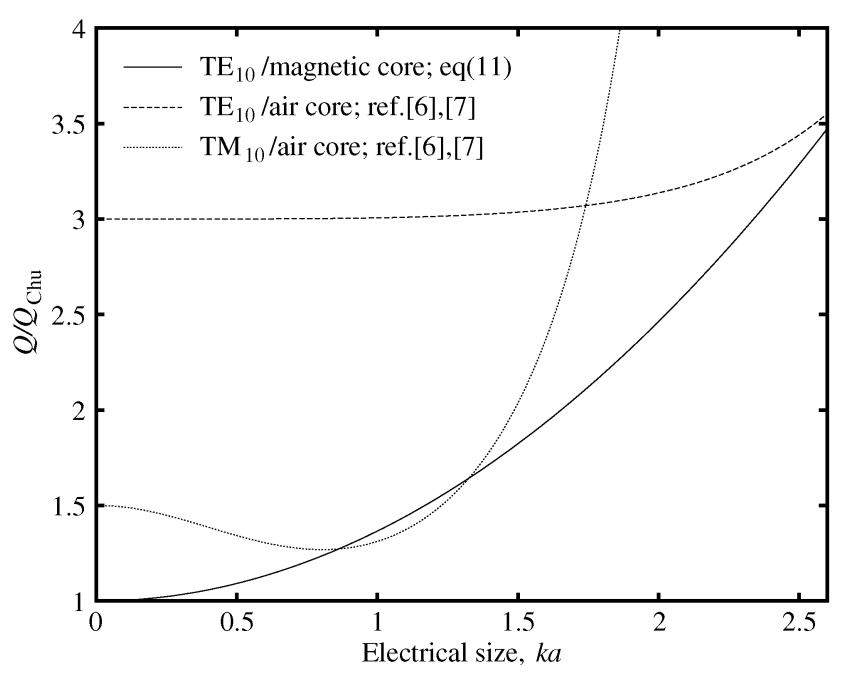

Fig. 3. The lower bound for magnetic dipole antennas with magnetodielectric core is compared to the bounds for air-core electric and magnetic dipole antennas [6], [7]. The bounds are normalized to the Chu lower bound $Q_{\mathrm{Chu}}$.

\section{RANGE OF VALIDITY}

All expressions given in Section II are exact and valid as long as the stored electric energy does not exceed the stored magnetic energy. Since these take turns in being dominant as the resonances are crossed, to define the range of validity for our expressions, we first need to find values of $\left(k a, \mu_{\mathrm{r}}, \varepsilon_{\mathrm{r}}\right)$, for which

$$
W_{\mathrm{H}}\left(k a, \mu_{\mathrm{r}}, \varepsilon_{\mathrm{r}}\right)=W_{\mathrm{E}}\left(k a, \mu_{\mathrm{r}}, \varepsilon_{\mathrm{r}}\right) .
$$

The first set of values corresponds to the total resonance

$$
\begin{aligned}
W_{\mathrm{H}}^{-}\left(k a, \mu_{\mathrm{r}}, \varepsilon_{\mathrm{r}}\right)+W_{\mathrm{H}}^{+}\left(k a, \mu_{\mathrm{r}}, \varepsilon_{\mathrm{r}}\right) & \\
& =W_{\mathrm{E}}^{-}\left(k a, \mu_{\mathrm{r}}, \varepsilon_{\mathrm{r}}\right)+W_{\mathrm{E}}^{+}\left(k a, \mu_{\mathrm{r}}, \varepsilon_{\mathrm{r}}\right)
\end{aligned}
$$

where $W_{\mathrm{H}}^{ \pm}$and $W_{\mathrm{E}}^{ \pm}$are, respectively, the magnetic and electric energies stored inside and outside the antenna core. The solution of (13) is not straightforward and has to be found numerically.

The second set of values is associated with the internal $\mathrm{TE}_{10}$-mode resonances in the spherical core of the antenna, when in the absence of the external fields the internal magnetic $W_{\mathrm{H}}^{-}$and electric $W_{\mathrm{E}}^{-}$stored energies are balanced

$$
W_{\mathrm{H}}^{-}\left(k a, \mu_{\mathrm{r}}, \varepsilon_{\mathrm{r}}\right)=W_{\mathrm{E}}^{-}\left(k a, \mu_{\mathrm{r}}, \varepsilon_{\mathrm{r}}\right) .
$$

In contrast to (13), the solution of (14) is known- $k_{s} a=v_{n}$, where $v_{n}$ are zeroes of the spherical Bessel function $j_{1}(v)$.

Since the bound (11) implies a pure magnetic core $\left(\varepsilon_{\mathrm{r}}=1\right)$, we can plot the result in a $\left(k a, \mu_{\mathrm{r}}\right)$ space, as shown in Fig. 4. Except for the shaded region, between the straight line representing the internal resonance (dependence $k_{s} a=v_{1}$ ) and a curve denoting the total resonance, the stored magnetic energy dominates over the stored electric energy. Thus, the optimum parameters (10), also shown in Fig. 4, corresponding to the lower bound (11) are located in the valid region $W_{\mathrm{H}}>W_{\mathrm{E}}$, which extends from the electrically small regime, $k a \ll 1$, up to $k a \approx 2.6$, at which (10) yields a total resonance. Consequently, the lower bound (11) is applicable in the range of antenna electrical sizes $0<k a<2.6$.

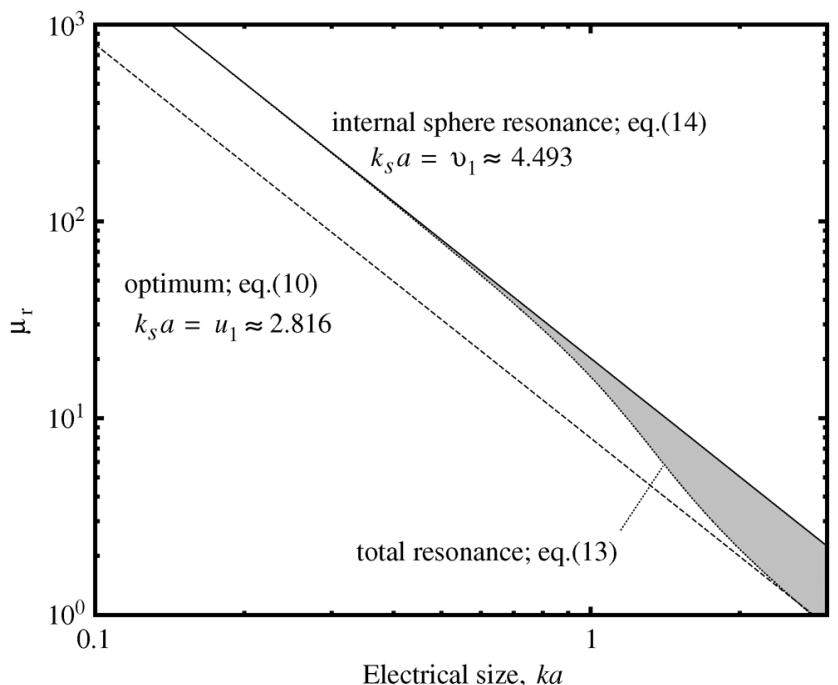

Fig. 4. Values $\left(k a, \mu_{\mathrm{r}}\right)$ corresponding to the resonances in a magnetic dipole antenna with a pure magnetic core $\left(\varepsilon_{\mathrm{r}}=1\right)$. For the parameters in the shaded region $W_{\mathrm{H}}<W_{\mathrm{E}}$. Optimum permeability (10) is also plotted.

\section{CONCLUSION}

The lower bound for the radiation $Q$ of magnetic dipole antennas with solid magnetodielectric core is derived explicitly. The bound can be reached by a spherical magnetic dipole antenna with a pure magnetic core, whose permeability is properly selected according to the antenna electrical size. Such an antenna exhibits a lower $Q$ than the air-core magnetic and electric dipole antennas of the same size in the range of $k a<0.863$ as well as for $1.325<k a<2.6$. The later value sets the upper limit for the range of validity of the presented bound.

\section{REFERENCES}

[1] H. A. Wheeler, "The spherical coil as an inductor, shield, or antenna," Proc. IRE, vol. 46, no. 9, pp. 1595-1602, 1958.

[2] H. L. Thal, "New radiation Q limits for spherical wire antennas," IEEE Trans. Antennas Propag., vol. 54, no. 10, pp. 2757-2763, Oct. 2006.

[3] L. J. Chu, "Physical limitations of omni-directional antennas," J. Appl. Phys., vol. 19, no. 12, pp. 1163-1175, 1948.

[4] O. S. Kim, O. Breinbjerg, and A. D. Yaghjian, "Electrically small magnetic dipole antennas with quality factors approaching the Chu lower bound," IEEE Trans. Antennas Propag., vol. 58, no. 6, pp. 1898-1906, Jun. 2010.

[5] J. S. McLean, "A re-examination of the fundamental limits on the radiation Q of electrically small antennas," IEEE Trans. Antennas Propag., vol. 44, no. 5, pp. 672-676, May 1996.

[6] O. Breinbjerg, "Stored energy and quality factor for spherical dipole antennas in free space," Tech. Univ. Denmark, 2009, Tech. Rep..

[7] R. Hansen and R. Collin, "A new Chu formula for Q," IEEE Antennas Propag. Mag., vol. 51, no. 5, pp. 38-41, 2009. 